\title{
Review Article \\ Chinese Herbal Medicine for the Treatment of Prehypertension
}

\author{
Jie Wang, Bo Feng, Xiaochen Yang, Wei Liu, and Xingjiang Xiong \\ Department of Cardiology, Guang'anmen Hospital, China Academy of Chinese Medical Sciences, \\ Beixiange 5, Xicheng District, Beijing 100053, China \\ Correspondence should be addressed to Xingjiang Xiong; 5administration@163.com
}

Received 29 May 2013; Accepted 19 June 2013

Academic Editor: Lixing Lao

Copyright (C) 2013 Jie Wang et al. This is an open access article distributed under the Creative Commons Attribution License, which permits unrestricted use, distribution, and reproduction in any medium, provided the original work is properly cited.

Objectives. To assess the current clinical evidence of Chinese herbal medicine (CHM) for prehypertension. Search Strategy. Electronic databases were searched until May, 2013. Inclusion Criteria. We included randomized clinical trials testing CHM against life style intervention and no treatment, or combined with life style intervention against life style intervention. Data Extraction and Analyses. Study selection, data extraction, quality assessment, and data analyses were conducted according to Cochrane standards. Results. Five trials were included. Methodological quality of the trials was evaluated as generally low. Only 1 trial reported allocation sequence. No trial reported the allocation concealment, double blinding, placebo control, presample size estimation, intention to treat analysis, and drop-out. All the included trials were not multicenter and large scale. Although meta-analysis showed that CHM is superior to either life style intervention group or no treatment group in decreasing blood pressure, we are unable to draw a definite conclusion on the effect of CHM due to the poor research methods used in the reviewed trials. The safety of CHM is still uncertain. Conclusions. There is no evidence to show that CHM is effective and safe for prehypertension due to serious methodological flaw of the reviewed trials. Rigorously designed trials are warranted to confirm these results.

\section{Introduction}

In 2003, the Seventh Joint National Committee on the Prevention, Detection, Evaluation, and Treatment of Hypertension (JNC-7) introduced a new category based on blood pressure (BP) level, called "prehypertension," to designate individuals whose systolic blood pressure (SBP) levels are in the range of 120 to $139 \mathrm{mmHg}$ and diastolic blood pressure (DBP) between 80 and $89 \mathrm{mmHg}[1,2]$. As compared to normal $\mathrm{BP}$, prehypertension is a precursor of clinical hypertension, which is associated with increased long-term risk and cardiovascular morbidity and mortality [3-5]. It is demonstrated by many researches that the rate of progression is determined mostly by age and resting blood pressure but may also be attenuated by increased fitness [6]. In recent observational studies in population-based samples with mean ages from 40 to 80 years, the risk of cardiovascular diseases (CVDs) increased progressively from levels as low as $115 / 75 \mathrm{mmHg}$ upward with a doubling of the incidence of both coronary heart disease and stroke for every $20 / 10 \mathrm{mmHg}$ increment of BP [7]. That is to say, the higher the BP, the greater the chance of heart attack, heart failure, stroke, and kidney diseases.
Currently, the prevention and management of prehypertension are the major public health challenges. According to JNC-7, the objective of defining this classification was to draw required clinical and public healthy attention and health promoting lifestyle modifications at an even earlier stage to prevent the progressive rise in BP and cardiovascular disease. Therefore, the primary goal of managing prehypertension is to lower $\mathrm{BP}$ into the normal range, prevent a rise in $\mathrm{BP}$ with age, and prevent BP-related CVDs events. Management consists of nonpharmacological interventions (including appropriate dietary pattern, weight loss, reduced sodium intake, regular physical activity, and moderation of alcohol intake) and pharmacological interventions [8, 9]. Perhaps if prehypertension was eliminated, almost half of all heart attacks could be prevented [10-12].

With the increasing enhancement of people's awareness of self-care, drugs with natural medicinal plants are increasingly favored by people all over the world for their unique advantages in preventing and curing diseases, rehabilitation, and health care [13-15]. In East Asia (especially China), a certain proportion of the population with prehypertension or hypertension has turned to complementary and alternative 
medicine (CAM), including Chinese herbal medicine (CHM) [16-19], for lowering BP and improving its related symptoms [20-22]. CHM, which is the most important component of traditional Chinese medicine (TCM), has a 3000-year-old history with unique theories for concepts of etiology and systems of diagnosis and treatment [23]. The knowledge about how to use them has been passed down through generations by word of mouth and ancient pharmacopoeias [24, 25]. Modern science has devoted considerable research to characterizing the efficacy and mechanisms of action of CHM. It is demonstrated that CHM has a vast array of bioactivities and is used in the management of various CVDs [26-29]. Recently, increasing number of clinical trials and systematic reviews (SRs) have been conducted, showing that CHM appears to be effective in lowering BP smoothly [30-36].

Until now, a number of clinical trials of CHM for prehypertension have been reported with positive findings [37-43]. However, there is no critically appraised evidence such as SRs or meta-analysis to assess clinical efficacy and safety of CHM for prehypertension. The paper aims to evaluate the current clinical evidence of CHM for prehypertension in randomized trials. To our knowledge, this is the first systematic English review on CHM for prehypertension.

\section{Methods}

2.1. Database and Search Strategies. The literature searches were conducted in the following 7 electronic databases: Cochrane Library (January, 2013), EMBASE (1980-2013), PubMed (1959-2013), Chinese National Knowledge Infrastructure (CNKI) (1980-2013), Chinese Scientific Journal Database (VIP) (1989-2013), Chinese Biomedical Literature Database (CBM) (1978-2013), and Wanfang data (1998-2013). The reference list of retrieved papers was also searched. Databases in Chinese were searched to retrieve the maximum possible number of trials of CHM for prehypertension because CHM is mainly practiced and studied in China. All of those searches ended on 1 May, 2013. Ongoing registered clinical trials were searched in the website of Chinese clinical trial registry (http://www.chictr.org/) and international clinical trial registry by US national institutes of health (http://clinicaltrials.gov/). The following search terms were used individually or combined: "prehypertension," "highnormal blood pressure," "blood pressure," "Chinese herbal medicine," "herb," "herbal medicine," "Chinese herb," "traditional Chinese medicine," "clinical trial," and "randomized controlled trial."

2.2. Inclusion Criteria. All the parallel randomized controlled trials (RCTs) of CHM used alone versus nonpharmacologic interventions, no treatment, and conventional western medicine were included. RCTs combined CHM with nonpharmacological interventions or conventional western medicine versus nonpharmacological interventions or conventional western medicine were included as well. There were no restrictions on population characteristics, language, and publication type. The main outcome measure was blood pressure. Duplicated publications reporting the same groups of participants were excluded.
2.3. Data Extraction and Quality Assessment. Two authors conducted the literature searching (X. J. Xiong, B. Feng), study selection (X. J. Xiong, X. C. Yang), and data extraction (X. J. Xiong, W. Liu) independently. The extracted data included authors, title of study, year of publication, study size, age and sex of the participants, study characteristics, diagnosis standard, details of methodological information, name and component of Chinese herbs, treatment process, details of the intervention and control, outcomes, and adverse effects for each study. Disagreement was resolved by discussion and reached consensus through a third party (J. Wang).

The methodological quality of trials was assessed independently using criteria from the Cochrane Handbook for Systematic Review of Interventions, Version 5.1.0 (X. J. Xiong, B. Feng) [44]. The items included the following 7 aspects: random sequence generation (selection bias), allocation concealment (selection bias), blinding of participants and personnel (performance bias), blinding of outcome assessment (detection bias), incomplete outcome data (attrition bias), selective reporting (reporting bias), and other bias. The quality of all the included trials was categorized to low/unclear/high risk of bias ("Yes" for a low risk of bias, "No" for a high risk of bias, "Unclear" otherwise). Then, trials were categorized into three levels: low risk of bias (all the items were in low risk of bias), high risk of bias (at least one item was in high risk of bias), unclear risk of bias (at least one item was in unclear risk of bias).

2.4. Data Synthesis. RevMan 5.1 software provided by the Cochrane Collaboration was used for data analyses. Dichotomous data were presented as risk ratio (RR) and continuous outcomes as mean difference (MD), both with 95\% confidence interval (CI). Heterogeneity was recognized significant when $I^{2} \geq 50 \%$. Fixed effects model was used if there is no significant heterogeneity of the data; random effects model was used if significant heterogeneity existed $\left(50 \%<I^{2}<\right.$ $85 \%)$. Publication bias would be explored by funnel plot analysis if sufficient studies were found.

\section{Result}

3.1. Description of Included Trials. As shown in Figure 1, the flow diagram depicted the search process and study selection. After primary searches from the above 7 electronic databases, 112 articles were retrieved. Fifty-Six articles were screened after 58 duplicates were removed. After reading the titles and abstracts, 28 articles were excluded. Full texts of 28 articles were retrieved, and 23 articles were excluded with reasons listed as below: participants did not meet the inclusive criteria $(n=18)$, duplication $(n=2)$, no control group $(n=1)$, and the intervention included other Chinese herbal formula $(n=2)$. Finally, 5 RCTs [45-49] were included. All of them were published in Chinese. The characteristics of included trials were listed in Table 1.

Four hundred and thirty prehypertensive patients were included. There was a wide variation in the age of subjects (23-75 years). Five trials specified the same diagnostic criteria of prehypertension, that is, Seventh Report of the Joint National Committee on Prevention, Detection, 


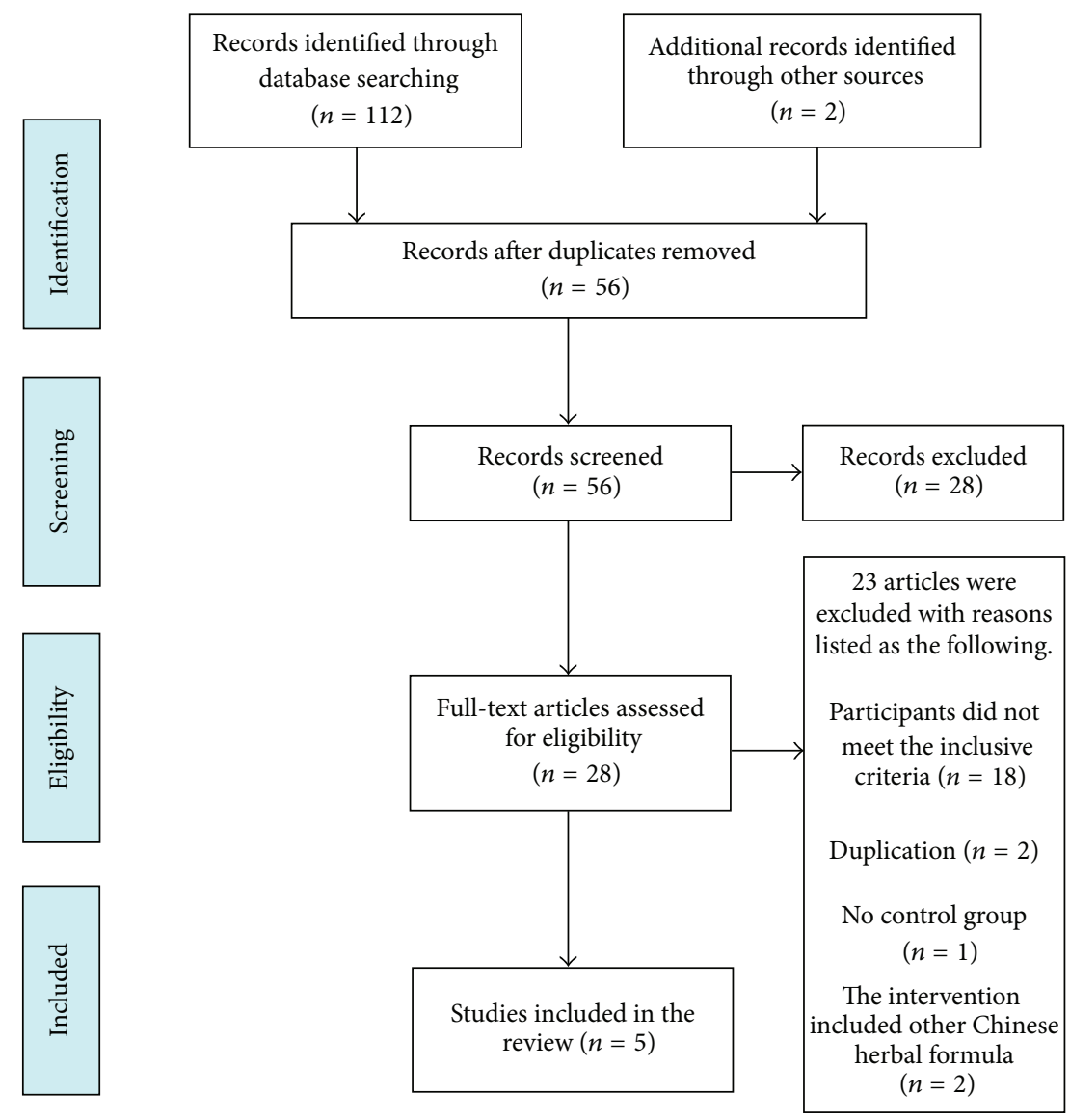

FIGURE 1: PRISMA 2009 flow diagram.

TABLE 1: Characteristics and methodological quality of included studies.

\begin{tabular}{|c|c|c|c|c|c|c|}
\hline Study ID & Sample & $\begin{array}{c}\text { Diagnosis } \\
\text { standard }\end{array}$ & Intervention & Control & Course (week) & $\begin{array}{c}\text { Outcome } \\
\text { measure }\end{array}$ \\
\hline Yang 2011 [45] & 90 & $\begin{array}{c}\text { JNC-7; } \\
\text { GCRNDTCM }\end{array}$ & $\begin{array}{c}\mathrm{CHM}\left(800 \mathrm{~mL} / \mathrm{d}^{\#}\right)+ \\
\text { control }\end{array}$ & $\begin{array}{c}\text { Life style } \\
\text { intervention }\end{array}$ & 4 & $\mathrm{BP}$ \\
\hline Li 2010 [46] & 80 & $\begin{array}{c}\text { JNC-7; } \\
\text { GCRNDTCM }\end{array}$ & $\begin{array}{c}\mathrm{BBTD}\left(400 \mathrm{~mL} / \mathrm{d}^{\#}\right)+ \\
\text { control }\end{array}$ & $\begin{array}{c}\text { Life style } \\
\text { intervention }\end{array}$ & 4 & $\mathrm{BP}$ \\
\hline Li et al. 2011 [47] & 123 & $\begin{array}{c}\text { JNC-7; TCM } \\
\text { diagnostic } \\
\text { criteria } \\
\text { (unclear) }\end{array}$ & RQSPD $\left(200 \mathrm{~mL} / \mathrm{d}^{\#}\right)$ & No treatment & 4 & $\mathrm{BP}$ \\
\hline Wu and Ding 2011 [48] & 80 & $\begin{array}{c}\text { JNC-7; } \\
\text { GCRNDTCM }\end{array}$ & $\begin{array}{l}\operatorname{TPKP}(1.2 \mathrm{gtid})+ \\
\text { control }\end{array}$ & $\begin{array}{c}\text { Life style } \\
\text { intervention }\end{array}$ & 8 & $\mathrm{BP}$ \\
\hline Zhang 2012 [49] & 57 & $\begin{array}{c}\text { JNC-7; TCM } \\
\text { diagnostic } \\
\text { criteria } \\
\text { (unclear) }\end{array}$ & BPLLD (1 bag bid) & $\begin{array}{l}\text { Life style } \\
\text { intervention }\end{array}$ & 12 & $\mathrm{BP}$ \\
\hline
\end{tabular}

Note: CHM: Chinese herb medicine; BBTD: Banxia baizhu tianma decoction; RQSPD: replenishing qi and strengthening spleen decoction; TPKP: tiao ping kang pill; BPLLD: blood pressure-lipid lowering decoction.

Evaluation, and Treatment of High Blood Pressure (JNC-7) [45-49]. Three trials have reported TCM diagnostic criteria according to Guidelines of Clinical Research of New Drugs of Traditional Chinese Medicine (GCRNDTCM) [45, 46, 48]. One trial reported prehypertensive patients with liver fire syndrome (LFS) [45]; 1 trial reported prehypertensive patients with abundant phlegm-dampness syndrome (PDS) [46]; 1 trial reported prehypertensive patients with LFS, PDS, yin deficiency with yang hyperactivity syndrome (YDYHS), and deficiency of both yin and yang syndrome (DYYS), 
respectively [48]. The other 2 trials have not reported any TCM diagnostic criteria at all $[47,49]$.

Interventions included CHM used alone or combined with life style intervention. The controls included life style intervention alone or no treatment. Three trials investigated CHM combined with life style intervention versus life style intervention $[45,46,48]$; 1 trial investigated CHM used alone versus no treatment [47]; 1 trial investigated CHM used alone versus life style intervention [49].

Total treatment duration ranged from 4 to 12 weeks. The variable prescriptions were presented in Table 1 . The different compositions of CHM were presented in Table 2. All of the 5 included trials used BP as the outcome measure. Adverse effect was described in details.

3.2. Methodological Quality of Included Trials. Methodological quality of the majority of the included trials was assessed to be low according to the predefined quality assessment criteria (as shown in Table 3). Randomized allocation of participants was mentioned in all trials; however, only 2 trials reported the methods for sequence generation including random number table $[45,46]$. No detailed information was provided in the other 3 trials to judge whether or not it was conducted properly [47-49]. Allocation concealment, blinding of participants and personnel, and blinding of outcome assessment were not mentioned in all included trials. None of the trials have reported drop-out or withdraw. A pretrial estimation of sample size was not reported in all the trials. One trial mentioned the follow-up with 6 months [46], while the other 4 trials did not mention it at all [45, 47-49]. We have also tried to contact the author by telephone, fax, and email for further detailed information about the trials; however, no information has been provided to date.

\subsection{Effect of the Interventions}

3.3.1. Chinese Herb Medicine Plus Life Style Intervention versus Life Style Intervention. Three trials reported the effect of CHM plus life style intervention versus life style intervention $[45,46,48]$. When it comes to systolic blood pressure (SBP), 2 trials demonstrated better effect favoring CHM: Banxia baizhu tianma decoction mildly lowered SBP than life style intervention treatment [46]; tiao ping kang pill significantly lowered SBP than life style intervention treatment [48]. Metaanalysis showed beneficial effect on the combination group as compared to the life style intervention group (WMD: -0.81 $[-1.16,-0.46] ; P<0.00001$ ) (as shown in Figure 2).

When it comes to diastolic blood pressure (DBP), 2 trials demonstrated better effect favoring CHM: Chinese herb medicine combined with life style intervention mildly lowered DBP than life style intervention [45]; the combination of tiao ping kang pill and life style intervention significantly lowered DBP than life style intervention [48]. Meta-analysis showed beneficial effect on the combination group as compared to the life style intervention group (WMD: -2.64 $[-2.75,-2.53] ; P<0.00001$ ) (as shown in Figure 3).
3.3.2. Chinese Herb Medicine versus Life Style Intervention. One trial reported CHM used alone versus life style intervention [49]. When it comes to SBP, meta-analysis showed that there is beneficial effect on the blood pressure-lipid lowering decoction group as compared to the life style intervention group (WMD: $-2.66[-3.75,-0.77] ; P=0.003$ ) (as shown in Figure 2).

When it comes to DBP, meta-analysis showed that there is beneficial effect on the blood pressure-lipid lowering decoction group as compared to the life style intervention group (WMD: $-1.78[-2.38,-1.18] ; P<0.00001$ ) (as shown in Figure 3).

3.3.3. Chinese Herb Medicine versus No Treatment. 1 trial reported CHM used alone versus no treatment [47]. When it comes to SBP, meta-analysis showed that there is significant beneficial effect on the replenishing qi and strengthening spleen decoction group as compared to no treatment group (WMD: $-6.10[-6.30,-5.90] ; P<0.00001$ ) (as shown in Figure 2).

When it comes to DBP, meta-analysis showed there is significant beneficial effect on the blood pressure-lipid lowering decoction group as compared to no treatment group (WMD: $-6.10[-6.22,-5.98] ; P<0.00001$ ) (as shown in Figure 3).

3.4. Publication Bias. The number of trials was too small to conduct any sufficient additional analysis of publication bias.

3.5. Adverse Effect. The outcome of adverse events (AEs) was reported in only 1 trial [49]. In the trial of Zhang 2012, no AEs were found in life style intervention group. AEs in CHM group included abdominal distension and diarrhea. And they were not serious. The other 4 trials have not been mentioned at all [45-48].

\section{Discussion}

Evidence suggests that individuals with $\mathrm{BP}$ close to the traditional threshold for the diagnosis of hypertension have a high likelihood of progression to BP meeting the definition of hypertension over the ensuing 5 years [50]. Therefore, the control of BP in a timely manner is of great significance for promoting cardiovascular health in prehypertensive patients. It is worth noting that the goal of therapy happens to coincide with ancient preventive medicine in TCM, that is, "the earlier the better for treating who and what are not yet ill [Sic]" in "Huang di nei jing" and "Nan jing" classics [29, 51, 52]. Due to the health-enhancing qualities of CHM, it has been dispensed and used in China for many years. Current researches demonstrated that $\mathrm{CHM}$ possess the advantage of whole body regulation in many ways for many targets. Recently, the continued study of the antihypertensive mechanisms of CHM for lowering $\mathrm{BP}$ has made great progress with regard to the etiology and pathogenesis of this disease. As an adjunctive treatment to antihypertensive drugs, $\mathrm{CHM}$ is a popular natural herbal product for prehypertension. However, the role of CHM for prehypertension is still unclear. This study 
TABLE 2: Composition of formula.

\begin{tabular}{|c|c|c|}
\hline Study ID & Formula & Composition of formula \\
\hline Yang $2011[45]$ & $\mathrm{CHM}$ & Mulberry leaves $10 \mathrm{~g}$, chrysanthemum $10 \mathrm{~g}$, hawthorn $10 \mathrm{~g}$, rose $10 \mathrm{~g}$. \\
\hline Li $2010[46]$ & BBTD & $\begin{array}{l}\text { Pinellia ternata } 10 \mathrm{~g} \text {, atractylodes macrocephala } 15 \mathrm{~g} \text {, gastrodia elata } 15 \mathrm{~g} \text {, tangerine } \\
\text { peel } 10 \mathrm{~g} \text {, poria cocos } 15 \mathrm{~g} \text {, glycyrrhiza } 5 \mathrm{~g} \text {, ginger } 10 \mathrm{~g} \text {, and red jujube } 10 \mathrm{~g} \text {. }\end{array}$ \\
\hline Li et al. 2011 [47] & RQSPD & $\begin{array}{l}\text { Lanceolata } 20 \mathrm{~g} \text {, kudzu root } 20 \mathrm{~g} \text {, astragalus } 15 \mathrm{~g} \text {, poria cocos } 15 \mathrm{~g} \text {, atractylodes } \\
\text { macrocephala } 15 \mathrm{~g} \text {, rhizoma atractylodes } 15 \mathrm{~g} \text {, coix lachryma-jobi } 15 \mathrm{~g} \text {, trichosanthin } \\
15 \mathrm{~g} \text {, pinellia ternata } 10 \mathrm{~g} \text {, and tangerine peel } 10 \mathrm{~g} \text {. }\end{array}$ \\
\hline Wu and Ding 2011 [48] & ТPКР & Ligustrum lucidum, epimedium, leonurus japonicus, and so forth. \\
\hline Zhang 2012 [49] & BPLLD & $\begin{array}{l}\text { Chrysanthemum, cassia seed, sophora flower, hawthorn, lotus leaf, alisma } \\
\text { orientalis, and green tea. }\end{array}$ \\
\hline
\end{tabular}

Note: CHM: Chinese herb medicine; BBTD: Banxia baizhu tianma decoction; RQSPD: replenishing qi and strengthening spleen decoction; TPKP: tiao ping kang pill; BPLLD: blood pressure-lipid lowering decoction.

TABLE 3: Quality assessment of included randomized controlled trials.

\begin{tabular}{|c|c|c|c|c|c|c|c|c|}
\hline Included trials & $\begin{array}{l}\text { Random } \\
\text { sequence } \\
\text { generation }\end{array}$ & $\begin{array}{l}\text { Allocation } \\
\text { concealment }\end{array}$ & $\begin{array}{c}\text { Blinding of } \\
\text { participants and } \\
\text { personnel }\end{array}$ & $\begin{array}{l}\text { Blinding of } \\
\text { outcome } \\
\text { assessment }\end{array}$ & $\begin{array}{c}\text { Incomplete } \\
\text { outcome } \\
\text { data }\end{array}$ & $\begin{array}{l}\text { Selective } \\
\text { reporting }\end{array}$ & $\begin{array}{c}\text { Other } \\
\text { sources of } \\
\text { bias }\end{array}$ & $\begin{array}{c}\text { Risk of } \\
\text { bias }\end{array}$ \\
\hline Yang 2011 [45] & $\begin{array}{c}\text { Table of random } \\
\text { number }\end{array}$ & Unclear & Unclear & Unclear & Yes & No & Unclear & Unclear \\
\hline Li $2010[46]$ & $\begin{array}{c}\text { Table of random } \\
\text { number }\end{array}$ & Unclear & Unclear & Unclear & Yes & No & Unclear & Unclear \\
\hline Li et al. 2011 [47] & Unclear & Unclear & Unclear & Unclear & Yes & No & Unclear & High \\
\hline Wu and Ding 2011 [48] & Unclear & Unclear & Unclear & Unclear & Yes & No & Unclear & High \\
\hline Zhang 2012 [49] & Unclear & Unclear & Unclear & Unclear & Yes & No & Unclear & High \\
\hline
\end{tabular}

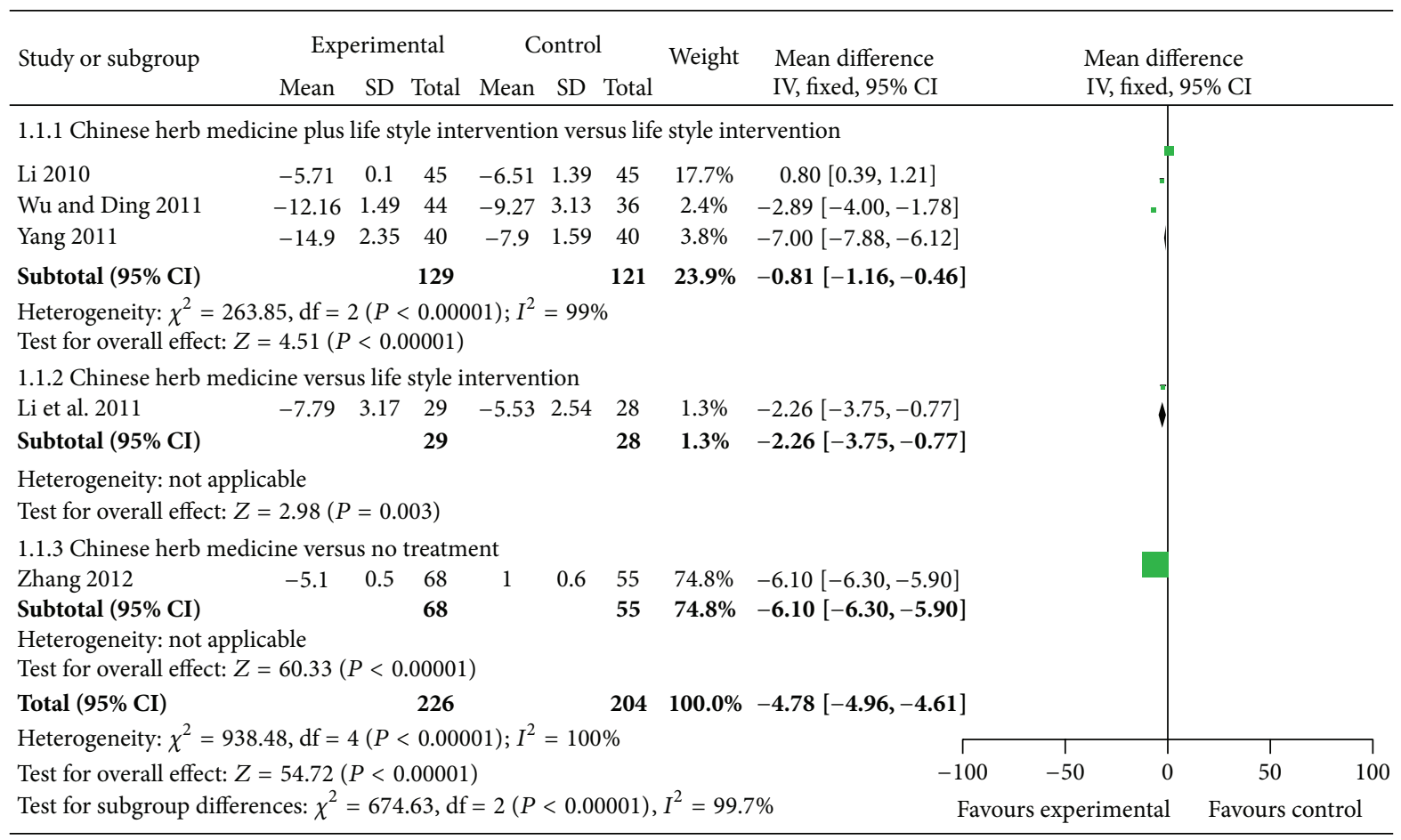

FIGURE 2: Analyses of systolic blood pressure (SBP). 


\begin{tabular}{|c|c|c|c|c|c|c|c|c|c|c|c|c|}
\hline \multirow[t]{2}{*}{ Study or subgroup } & \multicolumn{3}{|c|}{ Experimental } & \multicolumn{3}{|c|}{ Control } & \multirow{2}{*}{ Weight } & \multirow{2}{*}{$\begin{array}{l}\text { Mean difference } \\
\text { IV, fixed, 95\% CI }\end{array}$} & \multirow{2}{*}{\multicolumn{3}{|c|}{$\begin{array}{l}\text { Mean difference } \\
\text { IV, fixed, 95\% CI }\end{array}$}} & \\
\hline & Mean & SD & Total & Mean & SD & Total & & & & & & \\
\hline \multicolumn{13}{|c|}{ 1.1.1 Chinese herb medicine plus life style intervention versus life style intervention } \\
\hline Li 2010 & -4.43 & 0.45 & 45 & -2.63 & 0.07 & 45 & $35.7 \%$ & $-1.80[-1.93,-1.67]$ & & & & \\
\hline Wu and Ding 2011 & -9.48 & 2.91 & 44 & -9.2 & 0.94 & 36 & $0.8 \%$ & $-0.28[-1.19,0.63]$ & & - & & \\
\hline Yang 2011 & -12.7 & 0.66 & 40 & -7.9 & 0.12 & 40 & $14.6 \%$ & $-4.80[-5.01,-4.59]$ & & & & \\
\hline Subtotal $(95 \% \mathrm{CI})$ & & & 129 & & & 121 & $51.1 \%$ & $-2.64[-2.75,-2.53]$ & & & & \\
\hline \multicolumn{13}{|c|}{ Heterogeneity: $\chi^{2}=593.48, \mathrm{df}=2(P<0.00001) ; I^{2}=100 \%$} \\
\hline \multicolumn{13}{|c|}{ Test for overall effect: $Z=46.45(P<0.00001)$} \\
\hline \multicolumn{13}{|c|}{ 1.1.2 Chinese herb medicine versus life style intervention } \\
\hline Li et al. 2011 & -3.89 & 0.73 & 29 & -2.11 & 1.46 & 28 & $1.7 \%$ & $-1.78[-2.38,-1.18]$ & & & & \\
\hline $\begin{array}{l}\text { Subtotal }(95 \% \mathrm{CI}) \\
\text { Heterogeneity: not }\end{array}$ & licable & & 29 & & & 28 & $1.7 \%$ & $-1.78[-2.38,-1.18]$ & & & & \\
\hline \multicolumn{13}{|c|}{ Test for overall effect: $Z=5.79(P<0.00001)$} \\
\hline \multicolumn{13}{|c|}{ 1.1.3 Chinese herb medicine versus no treatment } \\
\hline Zhang 2012 & -5.9 & 0.2 & 68 & 0.2 & 0.4 & 55 & $47.1 \%$ & $-6.10[-6.22,-5.98]$ & & & & \\
\hline Subtotal $(95 \% \mathrm{CI})$ & & & 68 & & & 55 & $47.1 \%$ & $-6.10[-6.22,-5.98]$ & & & & \\
\hline \multicolumn{13}{|c|}{ Heterogeneity: not applicable } \\
\hline \multicolumn{13}{|c|}{ Test for overall effect: $Z=103.15(P<0.00001)$} \\
\hline Total $(95 \% \mathrm{CI})$ & & & 226 & & & 204 & $100.0 \%$ & $-4.25[-4.33,-4.17]$ & & & $T$ & \\
\hline \multicolumn{13}{|c|}{ Heterogeneity: $\chi^{2}=2445.05, \mathrm{df}=4(P<0.00001) ; I^{2}=100 \%$} \\
\hline \multicolumn{13}{|c|}{ Test for overall effect: $Z=104.78(P<0.00001)$} \\
\hline \multicolumn{13}{|c|}{ Test for subgroup differences: $\chi^{2}=1851.57, \mathrm{df}=2(P<0.00001) ; I^{2}=99.9 \%$} \\
\hline
\end{tabular}

FIgURE 3: Analyses of diastolic blood pressure (DBP).

aims to assess the current clinical evidence of CHM for prehypertension.

This systematic review included 5 randomized trials and a total of 430 participants. In this review, several CHMs demonstrated potential positive effect for prehypertension on either SBP or DBP. As compared to life style intervention group, positive results in SBP (WMD: $-0.81[-1.16,-0.46]$; $P<0.00001)$ and DBP (WMD: $-2.64[-2.75,-2.53] ; P<$ 0.00001 ) were found about Chinese herb medicine plus life style intervention group, indicating that SBP and DBP could be decreased by $0.81 \mathrm{mmHg}$ and $2.64 \mathrm{mmHg}$, respectively, after the combination therapy. As compared to life style intervention group, positive results in SBP (WMD: $-2.66[-3.75$, $-0.77] ; P=0.003$ ) and DBP (WMD: $-1.78[-2.38,-1.18]$; $P<0.00001)$ were found about Chinese herb medicine group, indicating that SBP and DBP could be decreased by $2.66 \mathrm{mmHg}$ and $1.78 \mathrm{mmHg}$, respectively, after CHM therapy. As compared to no treatment group, positive results in SBP (WMD: $-6.10[-6.30,-5.90] ; P<0.00001)$ and DBP (WMD: $-6.10[-6.22,-5.98] ; P<0.00001)$ were found about Chinese herb medicine group, indicating that SBP and DBP could be decreased by $6.10 \mathrm{mmHg}$ and $6.10 \mathrm{mmHg}$, respectively, after CHM therapy.

However, due to the poor methodological qualities, lack of placebo controlled trial and repeated test, small reduction in BP, and significant heterogeneity of included trials, available data are not adequate to draw a definite conclusion on the therapeutic effect and safety of CHM for prehypertension, although meta-analysis showed that CHM is superior to either life style intervention group or no treatment group in decreasing blood pressure. The following reasons might contribute to the inconclusive results.

Firstly, the quality of all the included RCTs is generally low, which were in accordance with previous studies [53, 54]. All the 5 trials included in this paper had risk of bias in terms of design, reporting, and methodology. They provided only inadequate reporting of study design, allocation sequence, allocation concealment, blinding, intention to treat analysis, and drop outs account in the majority of trials. Only 1 RCT stated randomization procedure with table of random number. However, most of them just mentioned that "prehypertensive patients were randomized into two groups" without detailed information. Thus, insufficient information has greatly restricted us to judge whether the randomization was conducted properly, which might lead to potential selection bias. None of the included RCTs reported the allocation concealment. Therefore, we could not rule out the possibility that some of these claimed RCTs are not real RCTs. Additionally, no RCTs claimed blinding of participants and personnel and blinding of outcome assessment, which directly led to performance bias and detection bias. Maybe there was difficulty in conducting the blinding of participants and personnel; however, none of the trials used blinding of outcome assessment, as the data analyzed by a third party could be conducted much easier. What is more, no RCTs used placebo control in the 5 included trials. Perhaps certain features associated with Chinese herbs such as aroma, color, and appearance did limit the clinical usage of placebo. However, it might exaggerate the effect of CHM due to the lacking of placebo, which was prone to generate significant systemic 
errors in the assessment of outcomes. All the included RCTs have not reported presample size estimation and drop-out. And most of the trials have not reported intention to treat analysis in details. All the included trials were not multicenter and large scale. As known to all, if poorly designed, the conclusions would show larger differences between welldesigned and poorly designed trials. Therefore, due to serious research methodological flaw in the included trials, the credibility of research findings in our review might be greatly reduced. And the reported beneficial effect from CHM for prehypertension cannot be taken as confirmative conclusion.

Secondly, there was a lack of knowledge about the significance of reporting AEs in the RCTs. AE is a critical issue in CAM which has raised more and more concern world widely [55-57]. In China, there is a general view that it seems to be safe to use CHM for various diseases $[58,59]$. In our review, most of the trials did not report the adverse effect of CHM except one [49]. Even for the trials that reported AEs by Zhang 2012, the report was very brief with insufficient information. Therefore, a definite conclusion about the safety of CHM cannot be made.

Thirdly, heterogeneity is worthy of being paid attention to. A total of 27 different Chinese herbs were investigated in the 5 RCTs. Great heterogeneity existed in these CHMs of this review. As a result, it is impossible to conduct any meaningful meta-analysis for a specific Chinese herb or difficult to undertake subgroup analyses to explore the specific factors that may have an impact on the effects of the treatment regimen.

Fourthly, a syndrome is a unique concept in TCM theory $[24,60]$. In the practice of TCM, CHM should be consistent with the type of syndrome differentiation. Therefore, TCM syndrome becomes the key issue both for RCT and clinical practice, which is also known as treatment based on individualized pattern and is thought to be the advantage of TCM [61, $62]$. However, in this systematic review, only 2 trials provide detailed information on patients' syndrome differentiation $[45,46]$. Two trials did not report any TCM diagnostic criteria $[47,49]$. One trial used tiao ping kang pill as the intervention; however, 4 TCM syndromes were reported, which have brought great confusion for further analysis [48]. We cannot exclude the possibility that the patients were not treated according to syndrome differentiation.

In conclusion, there is no convincing evidence of $\mathrm{CHM}$ for prehypertension due to poor methodological quality of included trials. To ensure evidence-based clinical practice, further rigorously designed placebo-controlled, randomized trials are warranted to confirm the results. The following methodological issues should be addressed carefully: (a) appropriate methods used in generating allocation sequence and allocation concealment; (b) double blinding (blinding of participants and personnel and blinding of outcome assessment) with the rational use of placebo; (c) strictly reporting withdrawal/dropout and the usage of intention to treat analysis; and (d) comprehensively reporting trials according to the CONSORT Statement [63]. We hope that with increasing publication of new high-qualified RCTs, more convincing clinical evidence would show whether or not $\mathrm{CHM}$ is safe and effective for prehypertension.

\section{Conflict of Interests}

All authors declare that they have no conflict of interests.

\section{Authors' Contribution}

Jie Wang and Bo Feng contributed equally to this paper.

\section{Acknowledgments}

The current work was partially supported by the National Basic Research Program of China (973 Program, no. 2003CB517103) and the National Natural Science Foundation Project of China (no. 90209011). The funders had no role in study design, data collection and analysis, decision to publish, or preparation of the paper.

\section{References}

[1] A. V. Chobanian, G. L. Bakris, H. R. Black et al., "The seventh report of the Joint National Committee on Prevention, Detection, Evaluation, and Treatment of High Blood Pressure: the JNC 7 Report," Journal of the American Medical Association, vol. 289, no. 19, pp. 2560-2572, 2003.

[2] A. V. Chobanian, G. L. Bakris, H. R. Black et al., "The Seventh report of the Joint National Committee on Prevention, Detection, Evaluation, and Treatment of High Blood Pressure," Hypertension, vol. 42, no. 6, pp. 1206-1252, 2003.

[3] A. I. Qureshi, M. F. K. Suri, J. F. Kirmani, A. A. Divani, and Y. Mohammad, "Is prehypertension a risk factor for cardiovascular diseases?” Stroke, vol. 36, no. 9, pp. 1859-1863, 2005.

[4] A. G. Mainous III, C. J. Everett, H. Liszka, D. E. King, and B. M. Egan, "Prehypertension and mortality in a nationally representative cohort," The American Journal of Cardiology, vol. 94, no. 12, pp. 1496-1500, 2004.

[5] M. de Marco, G. de Simone, M. J. Roman et al., "Cardiovascular and metabolic predictors of progression of prehypertension into hypertension: the strong heart study," Hypertension, vol. 54, no. 5, pp. 974-980, 2009.

[6] C. Faselis, M. Doumas, J. P. Kokkinos et al., "Exercise capacity and progression from prehypertension to hypertension," Hypertension, vol. 60, no. 2, pp. 333-338, 2012.

[7] S. Lewington, R. Clarke, N. Qizilbash, R. Peto, and R. Collins, "Age-specific relevance of usual blood pressure to vascular mortality: a meta-analysis of individual data for one million adults in 61 prospective studies," The Lancet, vol. 360, no. 9349, pp. 1903-1913, 2002.

[8] L. P. Svetkey, "Management of prehypertension," Hypertension, vol. 45, no. 6, pp. 1056-1061, 2005.

[9] M. F. Elias and A. L. Goodell, "Diet and exercise: blood pressure and cognition: to protect and serve," Hypertension, vol. 55, no. 6, pp. 1296-1298, 2010.

[10] A. V. Chobanian, "Prehypertension revisited," Hypertension, vol. 48, no. 5, pp. 812-814, 2006.

[11] S. P. Glasser, J. N. Basile, and D. T. Lackland, "Does prehypertension represent an increased risk for incident hypertension and adverse cardiovascular outcome?" Hypertension, vol. 54, no. 5, pp. 954-955, 2009.

[12] W. S. Weintraub, S. R. Daniels, L. E. Burke et al., "Value of primordial and primary prevention for cardiovascular disease: a policy statement from the American Heart Association," Circulation, vol. 124, no. 8, pp. 967-990, 2011. 
[13] P. A. Offit, "Studying complementary and alternative therapies," Journal of the American Medical Association, vol. 307, no. 17, pp. 1803-1804, 2012.

[14] J. A. Astin, "Why patients use alternative medicine: results of a national study," Journal of the American Medical Association, vol. 279, no. 19, pp. 1548-1553, 1998.

[15] H. Xu and K. J. Chen, "Complementary and alternative medicine: is it possible to be mainstream?" The Chinese Journal of Integrative Medicine, vol. 18, no. 6, pp. 403-404, 2012.

[16] F. Cheung, "TCM: made in China," Nature, vol. 480, no. 7378, pp. S82-S83, 2011.

[17] J. Wang and X. J. Xiong, "Current situation and perspectives of clinical study in integrative medicine in China," Evidence-Based Complementary and Alternative Medicine, vol. 2012, Article ID 268542, 11 pages, 2012.

[18] J. Wang and X. J. Xiong, "Control strategy on hypertension in Chinese medicine," Evidence-Based Complementary and Alternative Medicine, vol. 2012, Article ID 284847, 6 pages, 2012.

[19] C. Keji and X. Hao, "The integration of traditional Chinese medicine and Western medicine," European Review, vol. 11, no. 2, pp. 225-235, 2003.

[20] R. Nahas, "Complementary and alternative medicine approaches to blood pressure reduction: an evidence-based review," The Canadian Family Physician, vol. 54, no. 11, pp. 1529-1533, 2008.

[21] E. Ernst, "Complementary/alternative medicine for hypertension: a mini-review," Wiener Medizinische Wochenschrift, vol. 155, no. 17-18, pp. 386-391, 2005.

[22] M. C. Lin, R. Nahin, M. E. Gershwin, J. C. Longhurst, and K. K. $\mathrm{Wu}$, "State of complementary and alternative medicine in cardiovascular, lung, and blood research: executive summary of a workshop," Circulation, vol. 103, no. 16, pp. 2038-2041, 2001.

[23] X. Hao and C. Keji, "Integrative medicine: the experience from China," Journal of Alternative and Complementary Medicine, vol. 14, no. 1, pp. 3-7, 2008.

[24] J. Wang, P. Q. Wang, and X. J. Xiong, "Current situation and reunderstanding of syndrome and formula syndrome in Chinese medicine," Internal Medicine, 2012.

[25] X.-J. Xiong, "Study on the history of formulas corresponding to syndromes," Journal of Chinese Integrative Medicine, vol. 8, no. 6, pp. 581-588, 2010.

[26] H. Luo and H. Xu, "Outcome measures of Chinese herbal medicine for coronary heart disease: an overview of systematic reviews," Evidence-Based Complementary and Alternative Medicine, vol. 2012, Article ID 927392, 9 pages, 2012.

[27] J. Wang, X. J. Xiong, and B. Feng, "Cardiovascular effects of salvianolic acid B," Evidence-Based Complementary and Alternative Medicine, vol. 2013, Article ID 247948, 16 pages, 2013.

[28] J. Wang and X. J. Xiong, "Outcome measures of Chinese herbal medicine for hypertension: an overview of systematic reviews," Evidence-Based Complementary and Alternative Medicine, vol. 2012, Article ID 697237, 7 pages, 2012.

[29] X. J. Xiong, X. C. Yang, Y. M. Liu, Y. Zhang, P. Q. Wang, and J. Wang, "Chinese herbal formulas for treating hypertension in traditional Chinese medicine: perspective of modern science," Hypertension Research, 2013.

[30] J. Wang and X. J. Xiong, "Evidence-based Chinese medicine for hypertension," Evidence-Based Complementary and Alternative Medicine, vol. 2013, Article ID 978398, 12 pages, 2013.

[31] J. Wang, B. Feng, X. C. Yang et al., "Tianma gouteng yin as adjunctive treatment for essential hypertension: a systematic review of randomized controlled trials," Evidence-Based Complementary and Alternative Medicine, vol. 2013, Article ID 706125, 18 pages, 2013.

[32] X. J. Xiong, X. C. Yang, B. Feng et al., “Zhen gan xi feng decoction, a traditional Chinese herbal formula, for the treatment of essential hypertension: a systematic review of randomized controlled trials," Evidence-Based Complementary and Alternative Medicine, vol. 2013, Article ID 982380, 9 pages, 2013.

[33] J. Wang, X. C. Yang, B. Feng et al., "Is Yangxue Qingnao Granule combined with antihypertensive drugs, a new integrative medicine therapy, more effective than antihypertensive therapy alone in treating essential hypertension?" Evidence-Based Complementary and Alternative Medicine, vol. 2013, Article ID 540613, 8 pages, 2013.

[34] X. J. Xiong, X. C. Yang, W. Liu et al., "Banxia baizhu tianma decoction for essential hypertension: a systematic review of randomized controlled trials," Evidence-Based Complementary and Alternative Medicine, vol. 2012, Article ID 271462, 10 pages, 2012.

[35] J. Wang, K. W. Yao, X. C. Yang et al., "Chinese patent medicine liu wei di huang wan combined with antihypertensive drugs, a new integrative medicine therapy, for the treatment of essential hypertension: a systematic review of randomized controlled trials," Evidence-Based Complementary and Alternative Medicine, vol. 2012, Article ID 714805, 7 pages, 2012.

[36] J. Wang, X. J. Xiong, G. Y. Yang et al., "Chinese herbal medicine qi ju di huang wan for the treatment of essential hypertension: a systematic review of randomized controlled trials," EvidenceBased Complementary and Alternative Medicine, vol. 2013, Article ID 262685, 10 pages, 2013.

[37] X. Li and L. Wei, "Clinical research on early intervention of prehypertension and primary grade 1 hypertension by Qinggan jiangya drink," Zhongguo Shi Yan Fang Ji Xue Za Zhi, vol. 19, pp. 295-297, 2013.

[38] B. K. Zhou, Evaluation of Ziyin Pinggan Qianyang Decoction For Treating High-Normal Blood Pressure, Liaoning University of Chinese Medicine, Shenyang, China, 2010.

[39] F. L. Niu, Effect of Watermelon Supplementation on Blood Pressure in Chinese Adults With Prehypertension, Suzhou University, Suzhou, China, 2012.

[40] Q. Ding, The Influence of Blood Pressure Control By Way of Lifestyle Conversion Into Traditional Chinese Medicine Intervention on the Prehypertension Patients, Changchun University of Chinese Medicine, Changchun, China, 2012.

[41] B. K. Zhou and M. X. Zhang, "Clinical study of Ziyin pinggan qianyang decoction for treating high-normal blood pressure," Zhong Hua Zhong Yi Yao Xue Kan, vol. 29, pp. 364-369, 2011.

[42] H. Wu, S. X. Xian, and Y. Q. Ding, "Clinical short-term research on Tiao ping kang combined with life style intervention on patients with prehypertension," Zhongguo (Jiangmen) Guo Ji Zhong Xi Yi Jie He Xin Xue Guan Bing Xue Shu Hui Yi Lun Wen Hui Bian, pp. 180-183, 2010.

[43] J. J. Tong, "Effect of cassia seed on prehypertension," Zhongguo Min Jian Liao Fa, vol. 18, article 26, 2010.

[44] J. P. T. Higgins and S. Green, "Cochrane handbook for systematic reviews of interventions," The Cochrane Collaboration, 2009, http://www.cochrane-handbook.org/.

[45] C. Z. Yang, The Study of TCM Intervention of Prehypertension Affection and Clinical Research on Quality of Life, Beijing University of Chinese Medicine, Beijing, China, 2011. 
[46] M. M. Li, The Study of Clinical Intervention of Banxia Baizhu Tianma Decoction in Excessive Phlegm-Dampness Type Prehypertensive Patients, Guangzhou University of Chinese Medicine, Guangzhou, China, 2010.

[47] H. B. Li, G. H. Yue, S. Luo, H. Y. Liang, and J. M. Ding, "Effect of replenishing qi and strengthening spleen decoction on blood pressure in prehypertensive patients," Xin Zhong Yi, vol. 43, pp. 25-26, 2011.

[48] H. Wu and Y. Q. Ding, "Clinical effect of Tiao ping kang combined with life style intervention on patients with prehypertension," Hubei Zhong Yi Za Zhi, vol. 33, pp. 6-8, 2011.

[49] J. Zhang, Clinical Intervention of Blood Pressure-Lipid Lowering Decoction in Prehypertensive Patients, Shandong University of Chinese Medicine, Jinan, China, 2012.

[50] R. S. Vasan, M. G. Larson, E. P. Leip, W. B. Kannel, and D. Levy, "Assessment of frequency of progression to hypertension in non-hypertensive participants in the Framingham Heart Study: a cohort study," The Lancet, vol. 358, no. 9294, pp. 1682-1686, 2001.

[51] A. S. Ferreira, "Integrative medicine for hypertension: the earlier the better for treating who and what are not yet ill," Hypertension Research, 2013.

[52] X. J. Xiong, X. C. Yang, W. Liu, F. Y. Chu, P. Q. Wang, and J. Wang, "Trends in the treatment of hypertension from the perspective of traditional Chinese medicine," Evidence-Based Complementary and Alternative Medicine, vol. 2013, Article ID 275279, 13 pages, 2013.

[53] J.-L. Tang, S.-Y. Zhan, and E. Ernst, "Review of randomised controlled trials of traditional Chinese medicine," The British Medical Journal, vol. 318, no. 7203, pp. 160-161, 1999.

[54] J.-L. Tang, "Research priorities in traditional Chinese medicine," The British Medical Journal, vol. 333, no. 7564, pp. 391-394, 2006.

[55] K. Chan, "Some aspects of toxic contaminants in herbal medicines," Chemosphere, vol. 52, no. 9, pp. 1361-1371, 2003.

[56] H. Xu and K.-J. Chen, "Herb-drug interaction: an emerging issue of integrative medicine," The Chinese Journal of Integrative Medicine, vol. 16, no. 3, pp. 195-196, 2010.

[57] D. Melchart, K. Linde, W. Weidenhammer, S. Hager, and D. Shaw, "Liver enzyme elevations in patients treated with traditional Chinese medicine," Journal of the American Medical Association, vol. 282, no. 1, pp. 28-29, 1999.

[58] X.-J. Xiong, J. Wang, and Q.-Y. He, "Application status and safety countermeasures of traditional Chinese medicine injections," Journal of Chinese Integrative Medicine, vol. 8, no. 4, pp. 307311, 2010.

[59] X.-J. Xiong, J. Wang, and Q. Y. He, “Thinking about reducing adverse reactions based on idea of formula corresponding to syndromes," Zhongguo Zhongyao Zazhi, vol. 35, no. 4, pp. 536$538,2010$.

[60] X.-J. Xiong and J. Wang, "Discussion of related problems in herbal prescription science based on objective indications of herbs," Journal of Chinese Integrative Medicine, vol. 8, no. 1, pp. 20-24, 2010.

[61] A. P. Lu, Z. X. Bian, and K. J. Chen, "Bridging the traditional Chinese medicine pattern classification and biomedical disease diagnosis with systems biology," Chinese Journal of Integrative Medicine, vol. 18, no. 12, pp. 883-890, 2012.

[62] H. Xu and K.-J. Chen, "Integrating traditional medicine with biomedicine towards a patient-centered healthcare system," The Chinese Journal of Integrative Medicine, vol. 17, no. 2, pp. 83-84, 2011.
[63] D. Moher, S. Hopewell, K. F. Schulz et al., "CONSORT 2010 explanation and elaboration: updated guidelines for reporting parallel group randomised trials," International Journal of Surgery, vol. 10, no. 1, pp. 28-55, 2012. 


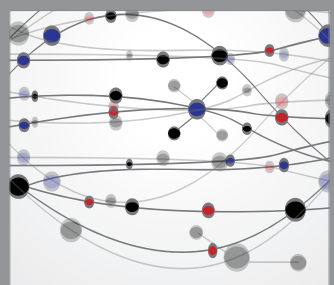

The Scientific World Journal
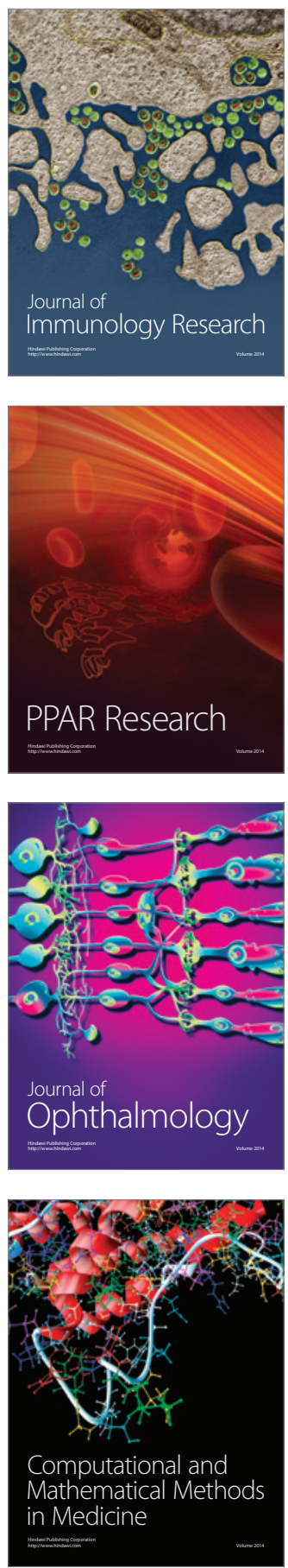

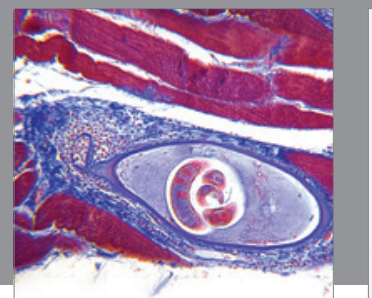

Gastroenterology

Research and Practice
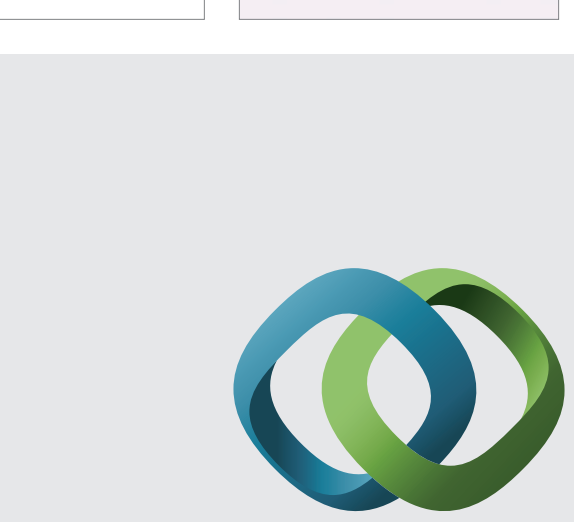

\section{Hindawi}

Submit your manuscripts at

http://www.hindawi.com
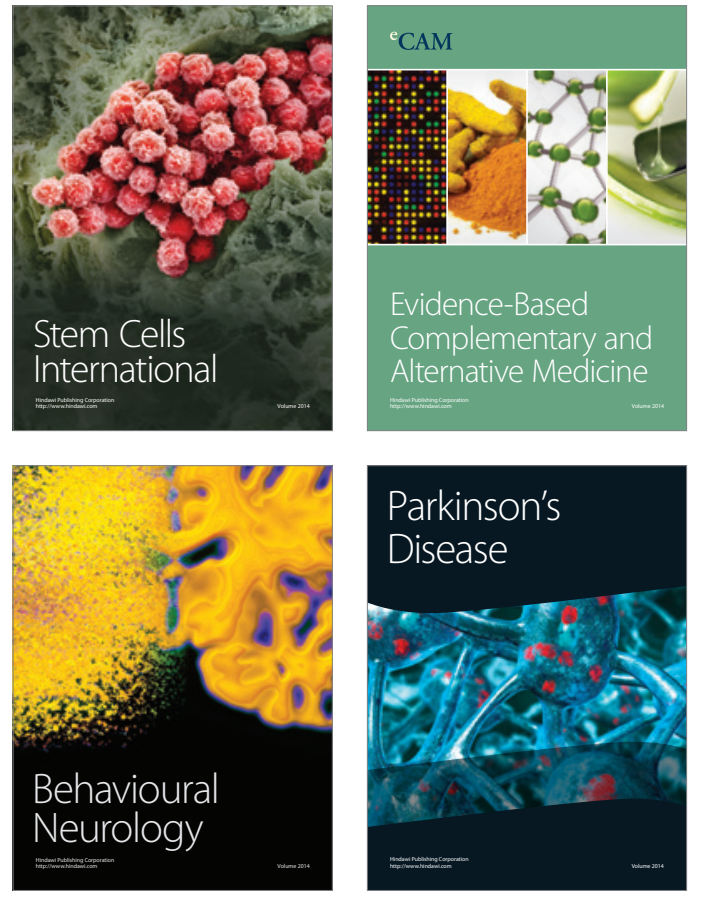
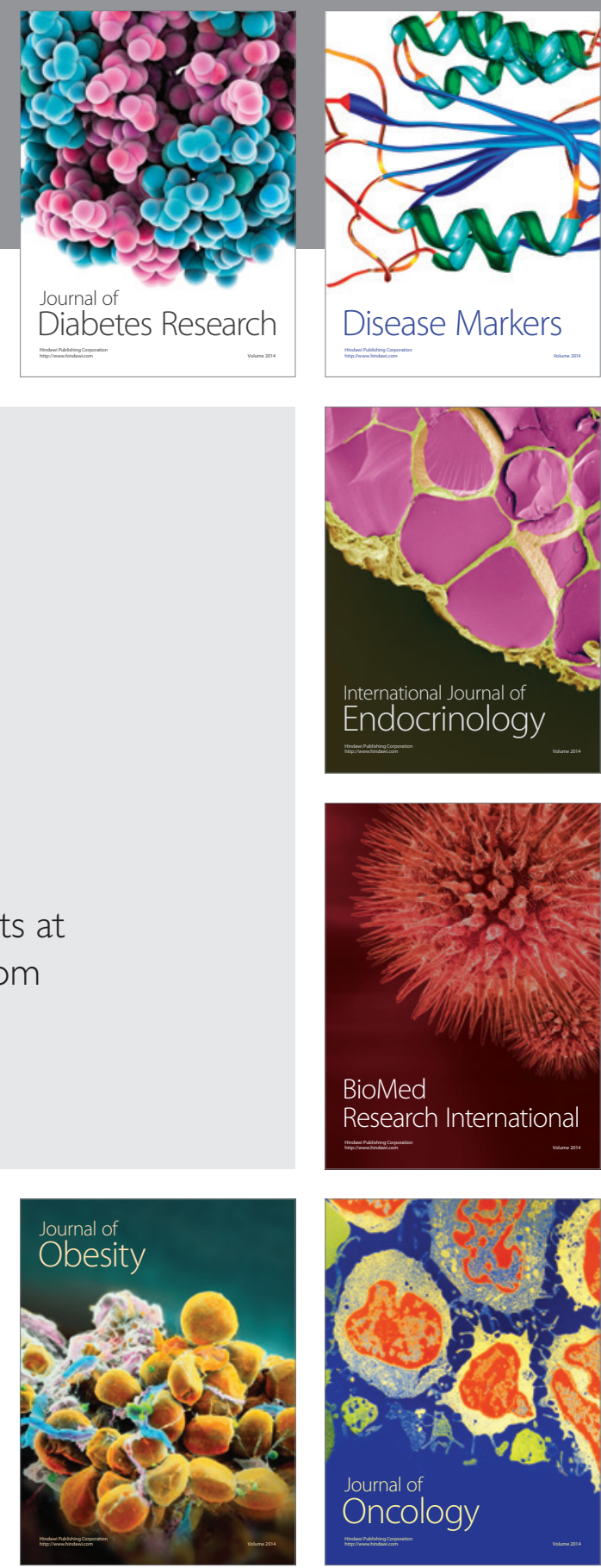

Disease Markers
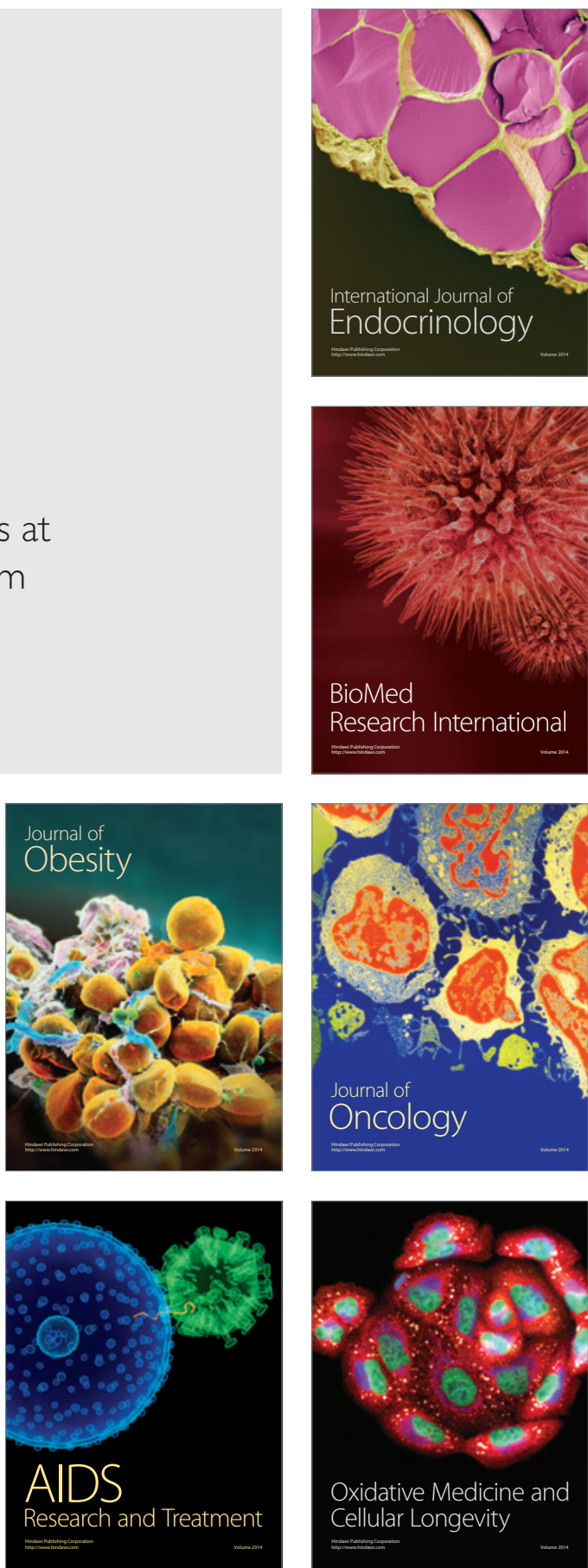